\title{
Improving Computer Engineering and Information Technologies Undergraduate Students' Training Through Combination of Formal, Non-Formal and Informal Learning
}

\author{
Oleksandr Malykhin \\ The Department of Romance and \\ Germanic Languages and Translation \\ National University of Life and \\ Environmental Sciences of Ukraine \\ Kyiv, Ukraine \\ malykhinalex1972@gmail.com
}

\author{
Nataliia Aristova \\ The Department of English Philology \\ National University of Life and \\ Environmental Sciences of Ukraine \\ Kyiv, Ukraine \\ n.aristova.na@gmail.com
}

\begin{abstract}
The paper analyses benefits of combining formal, non-formal and informal learning in Computer Engineering and Information Technologies undergraduate students' training. The results of research conducted in the 2017/2018 academic year are shown. A total of 106 students earning BA in Computer Engineering and Information Technologies at National University of Life and Environmental Sciences of Ukraine volunteered to participate in the research. The aim of the research was to investigate the influence of combining formal, nonformal and informal learning on improving Computer Engineering and Information Technologies undergraduate students' training through the increase in their general selfefficacy. To collect data from 106 computer engineering and information technologies undergraduate students we applied a mixed methods approach implying the combination of qualitative and quantitative methods. The quantitative data were collected using a pre-test and a post-test based on a questionnaire on general self-efficacy. Qualitative methods included classroom observations and interviews with computer engineering and information technologies undergraduate students. The authors compared the results obtained in the experimental and control groups and drew conclusions concerning the positive effects of combining formal, non-formal and informal learning on improving Computer Engineering and Information Technologies undergraduate students' training through the increase in their general self-efficacy.
\end{abstract}

Keywords-Computer Engineering and Information Technologies undergraduate students' training, formal learning, general self-efficacy, non-formal learning, informal learning.

\section{INTRODUCTION}

The intensive development of computer science and information technology due to the invention of the World Wide Web influences all aspects of human life in the digital era. As a result, specialists with jobs in the career fields of computer engineering and information technology are becoming more and more attractive in the eyes of prospective employers. In Ukraine the computer engineering and information technology training is regulated by the Ministry of Education and Science according to which earning a degree in this field requires students to complete at least undergraduate programmes at a higher educational institution. In this way students who are going to be computer engineers and IT professionals acquire hard and soft skills relevant to the range and complexity of tasks to be done at the working place. But are these skills enough to become successful after employment? Is formal learning provided by higher educational institutions enough to achieve the desired outcomes? What influences the strengthening of students' self-efficacy to fulfill various tasks during their training at university? Are students with a strong sense of self-efficacy more successful in acquiring the necessary skills and performing various tasks? These are some of the questions which are most frequently asked and for which educators and scientists all over the world are seeking answers to.

A considerable amount of scientific literature is documenting the fact that traditional learning regarded as formal one is no longer the only sufficient means of improving students' self-efficacy and as a consequence their skills necessary to meet ever changing requirements of the labour market [1], [2], [3], [4]. In almost all countries the standard education systems which regulate the professional training of specialists who will work in various industries have a static nature. It means that these systems do not always keep pace with the rapid development of new human knowledge and as a consequence respond to changing requirements by their up-to-date training. In this regard, the influence of the combination of formal, non-formal and informal learning 
on improving computer engineering and information technologies undergraduate students' training through the increase in their general self-efficacy is of particular interest in our research.

\section{The research has the following purposes:}

1. To share the experience of combining formal, nonformal and informal learning in computer engineering and information technologies undergraduate students' training at a higher educational institution.

2. To investigate the influence of combining formal, non-formal and informal learning on improving computer engineering and information technologies undergraduate students' training through the increase in their general self-efficacy.

\section{The Role of Formal, Non-formal and Informal} LEARNING IN IMPROVIng COMPUTER ENGINEERING AND Information Technologies Undergraduate Students' Training through the InCREASE In THeir Self-efFicacy

Many scientists are deeply convinced that selfefficacy plays a very important role in our lives. In fact, it was Bandura [5] who was the first one to state that self-efficacy influences people's beliefs on feelings, viewpoint, motivation and behaviour. Likewise, Tsang, Hui \& Law [6] specify that functioning as a multilevel and multifaceted set of views self-efficacy denotes people's confidence about their ability to fulfil various tasks. Cherry [7], in her study of self-efficacy, made it very clear that people with a strong sense of self-efficacy consider challenging issues as tasks to be mastered, take a greater interest in the activities they participate in, build a stronger sense of commitment to their interests and activities etc. At the same time Cherry [8] thinks that people whose sense of self-efficacy is weak believe that difficult tasks are beyond their capabilities, focus more on personal failings and negative outcomes, quickly lose confidence in personal abilities.

During professional training students usually face different challenges they have to overcome. Researchers' practical experience shows that students' abilities to overcome these challenges depend directly on the level of their self-efficacy [9], [10]. And although higher educational institutions provide students with various opportunities to improve their self-efficacy, in most cases formal learning cannot fully exert its influence on this process. We strongly believe that in order to maximize the impact of formal learning on improving students' self-efficacy universities have to provide non-formal and informal learning as well. Formal, non-formal and informal learning to different degrees provides four sources for developing self-efficacy beliefs, namely mastery experiences, vicarious experiences, verbal persuasion, emotional and psychological states [11]. Thus, formal learning is more connected with verbal persuasion, emotional and psychological states. It is probable due to the fact that during professional training students are surrounded by the faculty who try to make them think they can cope with any difficult task and they do not have to be afraid of any challenges. Non-formal and informal types of learning are linked with vicarious experiences as watching the success of their peers can play a crucial role in believing in your own abilities to cope with any task no matter how difficult it is.

Bearing in mind information mentioned above we can theorize that combination of formal, non-formal and informal learning influences the improvement of computer engineering and information technologies undergraduate students' training through the increase in their general self-efficacy.

Formal learning, for the purposes of our research, is defined as learning that occurs in an organised and structured environment [12]. It means that provided by different educational institutions it leads to validation and obligatory certification. In its turn, non-formal learning which occurs both at the learners' initiative or as a byproduct of educational establishment activities is rather organized and can have learning objectives [13]. It is provided by university partners who in most cases are prospective employers interested in young, active and highly motivated specialists. Unlike the formal and nonformal learning, informal one is unintentional, does not lead to certification and is not organised or structured in terms of objectives, time or learning support [14]. It is often defined as learning by experience as it does not have any objectives in terms of learning outcomes [15]. At higher educational institutions it is provided by scientific circles, clubs, themed contests etc.

At the Faculty of Information Technologies at National University of Life and Environmental Sciences of Ukraine formal learning is provided by five Departments, namely the Department of Computer Science, the Department of Computer systems and networks, the Department of Economic Cybernetics, the Department of Information Systems and the Department of Informational and Distant Technologies.

Non-formal learning is provided by the functioning of IT-Academies. Microsoft Imagine Academy and Cisco Academy enable students to get additional education and be certified as Microsoft Office Specialists, Microsoft Technology Associates, Microsoft Certified Solutions Developers and Microsoft Certified Solutions Experts and Cisco Certified Network Associates.

Four scientific circles which function at the Faculty of Information Technologies provide informal learning for students who earn their degrees in Computer Engineering and Information Technologies. These scientific circles are: the scientific circle in programming, the scientific circle "iTeam", the scientific circle "The Internet of things" and the scientific circle "Cybertonus". The operation of these circles aims at development of students' scientific and creative potential and what is more important at the improvement of their general self-efficacy. The university and faculty administration also organize various themed contests and club activities for students which assist in developing communication, team-working and timemanagement skills, ability to work under pressure etc. 


\section{Methodology of Research}

Computer Engineering and Information Technologies undergraduate students were selected as a research sample using a convenience sampling technique. The research was conducted at the Faculty of Information Technologies, National University of Life and Environmental Sciences of Ukraine (Kyiv). Experimental data were collected from 106 students earning BA in Computer Engineering and Information Technologies, 54 undergraduate students in the experimental group and 52 undergraduate students in the control group. Thus, 106 selected undergraduate students were informed about all types of activities organized by the faculty and university administration. But 54 computer engineering and information technologies undergraduate students who represented the experimental group were offered to become either members of scientific circles which function at the faculty or members of students' organization. The representatives of the experimental group were actively involved in all activities provided by non-formal and informal learning. The control group included 52 undergraduate students who were provided with formal learning only.

A mixed methods approach implying the combination of qualitative and quantitative methods was used to collect data from 106 Computer Engineering and Information Technologies undergraduate students.

The quantitative research used a pre-test and a posttest based on a questionnaire on general self-efficacy created by R. Schwarzer \& M. Jerusalem [16]. All the respondents were asked to rate the statements according to a 4-point scale (not at all true -1 point, hardly true -2 points, moderately true -3 points and exactly true 4 points) at the beginning and the end of experiment. In order to get a sum score we added up all the responses supplied by the respondents. The obtained results ranging from 10 to 26 points showed the low level of general selfefficacy, from 27 to 35 points - medium level of general self-efficacy and from 36 and higher - high level of general self-efficacy.

\section{Statements for assessment}

1. I can always manage to solve difficult problems if I try hard enough.

2. If someone opposes me, I can find means and ways to get what I want.

3. It is easy for me to stick to my aims and to accomplish my goals.

4. I am confident that I could deal efficiently with unexpected events.

5. Thanks to my resourcefulness, I know how to handle unforeseen situations.

6. I can solve most problems if I invest the necessary effort.

7. I can remain calm when facing difficulties because I can rely on my coping abilities.

8. When I am confronted with a problem, I can usually find several solutions.

9. If I am in a bind, I can usually think of something to do.

10. No matter what comes my way, I am usually able to handle it.
The qualitative methods used in the research comprised observation and interviews with Computer Engineering and Information Technologies undergraduate students. Like the quantitative methods, the qualitative ones made a great contribution to understanding the role of formal, non-formal and informal learning on increasing respondents' general self-efficacy and respondents' attitude towards participating in activities provided by three types of learning during Computer Engineering and Information Technologies professional training.

Two weeks prior to the beginning of the experimental work we at first interviewed 106 Computer Engineering and Information Technologies undergraduate students to understand their attitude towards opportunities provided by combining formal, non-formal and informal learning during their professional training. At second, all the respondents were asked to respond to the questionnaire developed by R. Schwarzer \& M. Jerusalem [17].

After interviewing and initial assessment of general self-efficacy the experimental and control groups were formed and the experimental work started. During the experimental work 54 Computer Engineering and Information Technologies undergraduate students were trained using the combination of formal, non-formal and informal learning whereas 52 students by means of formal learning only. To achieve the main aim of the research two hypotheses were formulated:

$\mathrm{H}$ 1: The combination of formal, non-formal and informal learning influences the improvement of Computer Engineering and Information Technologies undergraduate students' training through the increase in their general self-efficacy.

H 2: Formal learning which constitutes the standard learning required by the Ministry of Education and Science of Ukraine for earning a degree in the spheres of computer engineering and information technology provides the substantial increase in undergraduate students' general self-efficacy during their training.

\section{RESUlTS AND Discussion}

The results of the interviews carried out at the beginning of the experiment demonstrate that the students' opinions on combining formal, non-formal and informal learning during their training are different. Thus, 37,74\% $(\mathrm{n}=40)$ of respondents stated that formal learning is not enough to become a real professional. These respondents shared the common point of view:

Personally I think that formal learning is not enough for students who want to be good specialists in such spheres as computer engineering and information technology. These spheres are being developed rather quickly which means that knowledge and skills you obtain at university can become obsolete in a very short period of time. That is why during our training we have to pay more attention to all opportunities which are provided by university and which influence our self-development. There are different activities we can take part in beyond our classes. Some activities enable us to acquire additional knowledge and 
skills which are essential for becoming real professionals and which help us improve our confidence. But despite the fact that faculty administration always provides us with comprehensive information on seminars, webinars and various contests, it is your own choice to take part in them or not. It's a pity that some of us do not seize these opportunities.

$28,30 \%(n=30)$ of all the respondents shared the opinion that

Although during our training we are given opportunities to obtain additional training which will enhance our employability. For example, participating in scientific circles can improve not only our practical skills and intellectual abilities but also our abilities to work in a team, to cooperate and collaborate with other team members. Moreover, we can get some certificates completing different courses but you have to pay extra money to get them.

$33.96 \%(\mathrm{n}=36)$ of all the respondents argued that

To my mind, studying at university gives you basic background for being a good specialist in any sphere of human life. Skills and knowledge one can obtain at university is enough to start a career at any private or public organization. While you are a student it is difficult to understand what skills will be necessary at the working place. Another thing is that even if you get additional qualifications while you are training at university it doesn't mean you might need them in the future. You will understand what skills you lack when you start working. Only in this case you have to be involved in non-formal learning. As for informal learning, although university provides us with various opportunities, to tell the truth, it takes much time and effort to participate in activities after classes.

The analysis of respondents' ideas on incorporating the combination of formal, non-formal and informal learning into professional training of Computer Engineering and Information Technologies undergraduate students expressed during their interviewing enabled researchers to form maximally homogenous experimental and control groups. As it was mentioned above there were 54 Computer Engineering and Information Technologies undergraduate students in the experimental group and 52 Computer Engineering and Information Technologies undergraduate students in the control one. A fairly equal distribution of respondents who expressed different points of view on combining formal, non-formal and informal learning during their professional training enabled researchers, on the one hand, to do the experiment in the natural conditions and, on the other hand, to consider their attitudes towards additional opportunities provided by non-formal and informal learning.

The results of data analysis related to finding out the levels of general self-efficacy by the experimental and control groups at the beginning of the experiment are presented in Table 1.
TABle 1 Respondents' GENERAL SELF-EFFICACy LEVELS AT THE BEGINNING OF THE EXPERIMENT

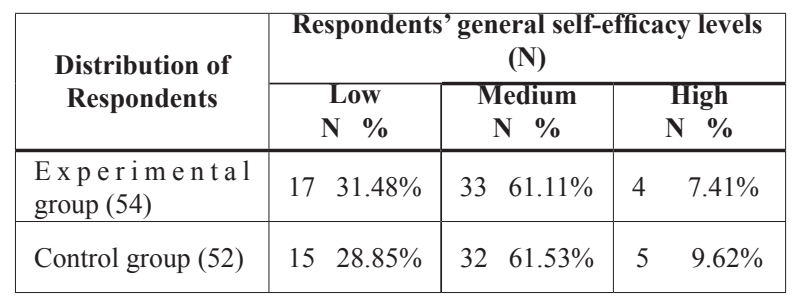

As we can see in Table 1, there was no clear difference in computer engineering and information technologies undergraduate students' general self-efficacy levels at the beginning of the experiment. Thus, $31.48 \%(n=17)$ of respondents in the experimental group and $28.85 \%$ $(\mathrm{n}=15)$ of respondents in the control group had a low level of general self-efficacy. Medium level of general selfefficacy was shown by $61.11 \%(n=33)$ of the experimental group respondents and $61.53 \%(n=32)$ of the control group respondents. High level of general self-efficacy was shown by $7.41 \%(n=4)$ of respondents in the experimental group and $9.62 \%(n=5)$ of respondents in the control group.

The results of data analysis related to finding out the levels of general self-efficacy by the experimental and control groups at the end of the experiment are presented in Table 2.

TABLE 2 ResPondents' GeNERAL SELF-EFFICACY LEVELS AT THE END OF THE EXPERIMENT

\begin{tabular}{|c|c|c|c|}
\hline \multirow{3}{*}{$\begin{array}{c}\text { Distribution of } \\
\text { Respondents }\end{array}$} & \multicolumn{3}{|c|}{$\begin{array}{l}\text { Respondents' general self-efficacy levels } \\
\text { (N) }\end{array}$} \\
\hline & Low & Medium & High \\
\hline & N \% & N \% & N $\%$ \\
\hline $\begin{array}{l}\text { Experime n t a l } \\
\text { group (54) }\end{array}$ & $0 \%$ & $4481.48 \%$ & $18.52 \%$ \\
\hline Control group (52) & $10 \quad 19.23 \%$ & $37 \quad 71.15 \%$ & $9.62 \%$ \\
\hline
\end{tabular}

As it is shown in Table 2 at the end of the experiment the experimental group whose formal learning at the Faculty of Information Technologies was combined with non-formal and informal learning showed higher levels of general self-efficacy that the control group. Thus, low level of general self-efficacy was demonstrated by $0 \%(\mathrm{n}=0)$ of respondents in the experimental group, medium level of general self-efficacy by $81.48 \%(n=44)$ of respondents and high level by $18.52 \%(n=10)$ of respondents. Unlike the experimental group, the results shown by the control group were considerably lower. $19.23 \%(n=10)$ of respondents in the control group had a low level of general self-efficacy, $71.15 \%(n=37)-$ medium level and only $9.62 \%(n=5)-$ high level.

The results of data analysis regarding comparison of the general self-efficacy levels by the experimental and control groups at the beginning and the end of the experiment are given in Table 3. 
TABLE 3 The COMPARISON OF RESPONDENTS' GENERAL SELF-EFFICACY LEVELS AT THE BEGINNING AND THE END OF THE EXPERIMENT

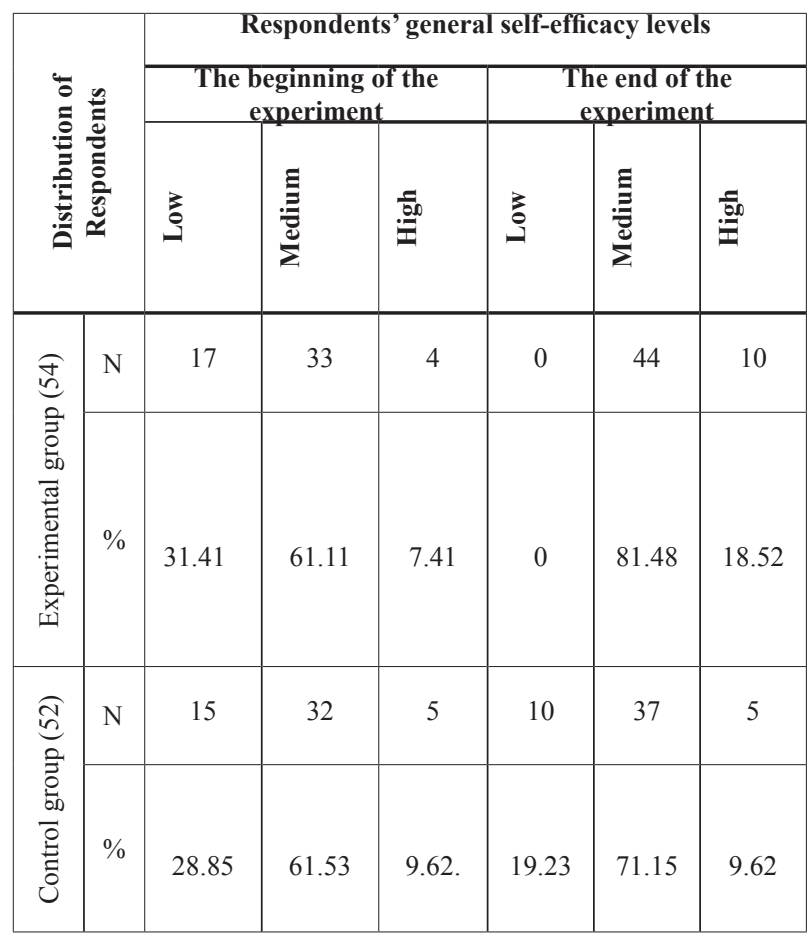

By comparing the results obtained at the beginning and the end of the experiment, we can state that if before the experimental work a low level of general-self efficacy was shown by $31.48 \%(\mathrm{n}=17)$ of respondents in the experimental group and $28.85 \%(\mathrm{n}=15)$ of respondents in the control group after the experimental work it was demonstrated by $0 \%(n=0)$ of respondents in the experimental group and $19.23 \%(n=10)$ of respondents in the control group. At the beginning of the experiment a medium level of general self-efficacy was demonstrated by $61.11 \%(n=33)$ of the experimental group respondents and $61.53 \%(\mathrm{n}=32)$ of the control group respondents while at the end of the experiment it was shown by $81.48 \%$ $(n=44)$ in the experimental group and $71.15 \%(n=37)$ in the control group. At the beginning of the experiment $7.41 \%(n=4)$ of respondents in the experimental group and $9.62 \%(n=5)$ of respondents in the control group showed a high level of general self-efficacy whereas at the end of the experiment a high level of general selfefficacy was shown by $18.52 \%(\mathrm{n}=10)$ of respondents in the experimental group and $9.62 \%(n=5)$ of respondents in the control group. Thus, taking into account the obtained results we can assert that there has been a significant increase in general self-efficacy levels by the experimental group. Moreover, the results of the research confirm our idea about necessity of incorporating nonformal and informal learning into computer engineering and information technologies undergraduate students' training. Such a combination of formal, non-formal and informal learning increased computer engineering and information technologies undergraduate students' general self-efficacy and as a consequence improved their training.

Thus, the first hypothesis concerning the influence of combining formal, non-formal and informal learning on the improvement of computer engineering and information technologies undergraduate students' training through the increase in their general self-efficacy was confirmed.

The second hypothesis that formal learning provides the substantial increase in computer engineering and information technology undergraduate students' general self-efficacy during their training was rejected.

\section{CONCLUSION}

The main purposes of the research were to share the experience of combining formal, non-formal and informal learning in computer engineering and information technologies undergraduate students' training at a higher educational institution and to investigate the influence of combining formal, non-formal and informal learning on improving computer engineering and information technologies undergraduate students' training through the increase in their general self-efficacy. The obtained findings showed that undergraduate students involved in additional activities provided the combination of formal, non-formal and informal learning at the Faculty of Information Technologies benefited greatly in increasing their general self-efficacy.

The research concluded that providing formal, nonformal and informal learning in isolation denied computer engineering and information technologies undergraduate students the possibility of substantial increase in their general self-efficacy. Formal learning provides students with skills and competences necessary for their employability but it is not enough to teach them to cope with all the difficulties they face. Understanding what way the incorporation of non-formal and informal learning into the formal one relates to the increase of general selfefficacy allows the faculty to benefit fully in improving computer engineering and computer technologies undergraduate students' training.

Although educators and researchers dealing with improvement of undergraduate students' training through the increase in their self-efficacy can take into consideration the implications of the present study, further research is recommended in this area.

\section{REFERENCES}

[1] M. E. Gist, “ The Effects of Self-Efficacy Training on Training Task Performance," Academy of Management Proceedings, vol. 1986, no. 1, pp. 250-254, 1986.

[2] O. Malykhin and N.Aristova, "Investigation into participation activity rate of foreign languages teachers in specially focused network pedagogical communities," The New Pedagogical Review, vol. 53, no. 3, pp. 227-238, 2018, DOI: 10.15804/tner.2018.53.3.19

[3] Recognition of Non-formal and Informal: Learning Pointers for policy development, March 2010. [Online]. Available: file:///C:/ Users/Asus/Desktop/non-formal $\% 20$ and $\% 20$ formal $\% 20$ learning.pdf [Accessed: Dec. 22, 2018].

[4] M. Radaković and S. Antonijević, " Balance between formal and informal learning - experience and challenges of civil servants training in Serbia", 2013. [Online]. Available: http://www.nispa.org/files/conferences/2013/ papers/201304151202190.Paper_Radakovic.pdf. [Accessed: Dec. 12, 2018].

[5] A. Bandura, "Perceived Self-Efficacy in Cognitive Development and Functioning,". Educational Psychologist, vol. 28, no. 2, pp. 117-148, 1993.

[6] S. K. M. Tsang, E. K. P. Hui and B. C. M. Law, "Self-Efficacy 
as a Positive Youth Development Construct: A Conceptual Review", The Scientific World Journal, April 2012. [Online]. Available: https:// www.ncbi.nlm.nih.gov/pmc/articles/PMC3351108 [Accessed: Nov. 7, 2018].

[7] K. Cherry, "Self-Efficacy: Why believing in yourself matters," August 2018. [Online]. Available: https://www. verywellmind.com/what-is-self-efficacy-2795954. [Accessed: Dec.10, 2018].

[8] K. Cherry, "Self-Efficacy: Why believing in yourself matters," August 2018. [Online]. Available: https://www. verywellmind.com/what-is-self-efficacy-2795954. [Accessed: Dec.10, 2018].

[9] M. E. Gist, "The Effects of Self-Efficacy Training on Training Task Performance," Academy of Management Proceedings, vol. 1986 , no. 1 , pp. 250-254, 1986.

[10] K. Cherry, "Self-Efficacy: Why believing in yourself matters," August 2018. [Online]. Available: https://www. verywellmind.com/what-is-self-efficacy-2795954. [Accessed: Dec.10, 2018].

[11] A. Bandura, (1977). "Self-efficacy: Toward a Unifying Theory of Behavioral Change," Psych. Rev., vol. 84, no. 2, pp. 191$215,1977$.
[12] Terminology of European education and training policy. (2008). [Online]. Available: http://www.cedefop.europa.eu/ files/4064_en.pdf

[13] Recognition of Non-formal and Informal: Learning Pointers for policy development, March 2010. [Online]. Available: file:///C:/ Users/Asus/Desktop/non-formal $\% 20$ and $\% 20$ formal $\% 20$ learning.pdf [Accessed: Dec. 22, 2018].

[14] Terminology of European education and training policy. (2008). [Online]. Available: http://www.cedefop.europa.eu/ files/4064 en.pdf

[15] Recognition of Non-formal and Informal: Learning Pointers for policy development, March 2010. [Online]. Available: file:///C:/ Users/Asus/Desktop/non-formal $\% 20$ and $\% 20$ formal $\% 20$ learning.pdf [Accessed: Dec. 22, 2018].

[16] R. Schwarzer and M. Jerusalem, "Generalized Self-Efficacy scale," in J. Weinman, S. Wright, \& M. Johnston, Measures in health psychology: A user's portfolio. Causal and control beliefs, Windsor, England: NFER-Nelson, 1995, pp. 35-37.

[17] R. Schwarzer and M. Jerusalem, "Generalized Self-Efficacy scale," in J. Weinman, S. Wright, \& M. Johnston, Measures in health psychology: A user's portfolio. Causal and control beliefs, Windsor, England: NFER-Nelson, 1995, pp. 35-37. 